\title{
Evaluation of the Illinois Change of Direction Test in Youth Elite Soccer Players of Different Age
}

\author{
by \\ Yassine Negra1, Helmi Chaabene2,3, Samiha Amara ${ }^{4}$, Slobodan Jaric ${ }^{5,6,7}$, \\ Mehréz Hammami ${ }^{1}$, Younés Hachana ${ }^{1,4}$
}

\begin{abstract}
Change of direction ability is an essential pre-requisite in team sports athletes. The Illinois change of direction test has been routinely used for testing change of direction ability in soccer players. The aim of the present study was to evaluate the Illinois change of direction test in young elite soccer players in terms of its reliability, usefulness and relationship with body size. A total of one hundred and ninety-four male, national-level soccer players were recruited. They were classified into four age groups (U-8, U-10, U-12 and U-14). Participants were tested using the Illinois change of direction test twice, and basic indices of body size were obtained. The Illinois change of direction scores showed high relative and absolute reliability in all age groups (all intraclass correlation coefficients were $>0.91$, and the standard error of measurement was $<5 \%$ ). The usefulness analysis showed that the Illinois change of direction test could detect small changes in performance in the U-10 and U-12 groups. However, it could only detect moderate changes in performance in the U-8 and U-14 groups. Although the Illinois change of direction test detected significant performance differences among groups, scores were not significantly related to body size $(-0.30<r<0.15 ; p>0.05)$. Taking into account the test's high reliability and the appropriate level of usefulness, these results might support the use of the Illinois change of direction test as a standard measure for quantifying change of direction ability in young soccer players.
\end{abstract}

Key words: change of direction; reliability; body size; normalization.

\section{Introduction}

The ability to move at high speeds and quickly execute changes of direction (CODs) is a prerequisite for successful participation in many team sports, including soccer (Luhtanen, 1994). Although these actions could make the difference in determining the outcome of a game, they only represent $11 \%$ of the total distance covered during a typical game (Reilly et al., 2000). During a soccer match, a COD occurs every 2 to 4 seconds (Davids et al., 2000), and soccer players change direction between 1,200 and 1,400 times over the course of a game (Bangsbo, 1992). Indeed, Bloomfield et al. (2007) showed that Premier league soccer players, regardless of positional classification (i.e., defender, midfielder, striker), performed the equivalent of $726 \pm 203$ turns during a match, with $609 \pm 193$ of these being of $0^{\circ}$ to $90^{\circ}$ to the left or

\footnotetext{
1 - Research Unit "Sport Performance, Health \& Society" Higher Institute of Sport and Physical Education of Ksar Said, Tunis, Tunisia.

2 - Tunisian Research Laboratory "Sports Performance Optimization", National Center of Medicine and Science in Sports (CNMSS), Tunis, Tunisia.

3- High Institute of Sports and Physical Education, Kef, University of Jendouba, Tunisia

4 - Higher Institute of Sports and Physical Education, Manouba University, Tunis, Tunisia.

5 - Department of Kinesiology and Applied Physiology \& Biomechanics and Movement Science Graduate Program, University of Delaware, Newark, USA.

6 - Department of Human Motor Behavior, The Jerzy Kukuczka Academy of Physical Education in Katowice, Poland.

7. Faculty of Sport and Physical Education, University of Belgrade, Serbia
} 
right. A soccer match also requires other highspeed actions that involve rapid acceleration and maximal speed, and therefore, COD ability is one of the crucial physical abilities necessary for successful game performance (Little and Williams, 2005). In particular, COD performance is important for soccer players as numerous situations within the game require a sudden COD in response to a stimulus, such as an action of a teammate, an opponent or the ball (Sheppard and Young, 2006). Lloyd and Olivier (2012) highlighted the need for a structured approach to COD development throughout childhood and adolescence. In this context, Mirkov et al. (2010) emphasized that performing a COD could be a crucial factor in determining the future success of 11-year-old players. Therefore, COD ability should be taken into consideration for both the early selection and the routine assessment of players.

Several studies have suggested that COD performance gradually increases as children mature, albeit in a nonlinear manner (Chiodera et al., 2008; Vänttinen et al., 2011). This trend has been reinforced by recent studies indicating that agility is significantly lower at the age of 12 than it is at 14 (Jakovljevic et al., 2012). It has also been argued that the peak rate of development of COD performance occurs at approximately 13 to 14 years of age in male soccer players, which is commonly considered to be the period at which the rate of height increase peaks (Vänttinen et al., 2011). A model recently proposed by Lloyd et al. (2013) suggests that the percentage of training time dedicated to COD development in prepubertal, circumpubertal, and postpubertal children should be 25,40 and $20 \%$, respectively, indicating that COD training is a function of the player's maturational stage.

According to Malina et al. (2004), boys with advanced sexual and skeletal maturity are stronger, faster and more powerful than boys who undergo late maturation. This phenomenon could result in a spurious relationship between COD performance and body size. Although movement velocity and COD should not be related to body size (Jaric, 2003; Sheppard and Young, 2006), there is some evidence that a difference in the onset of maturation could confound that relationship (Jaric et al., 2002; Nedeljkovic et al., 2007). In addition, Lloyd et al. (2013) revealed that apart from technique, straight-line running speed, lower-limb strength, lower-limb power and anthropometric variables could be important contributors to COD performance. However, both muscle strength and power have been positively correlated with body size (Jaric, 2003). Therefore, it remains unknown whether COD measurements obtained from young athletes should be normalized for body size.

The Illinois change of direction test (ICODT) has often been considered a standard protocol for assessing COD performance (Draper and Lancaster, 1985). Apart from high overall validity (Hachana et al., 2013), the test could have an advantage in terms of ecological validity as it includes generic cues that closely replicate the majority of movement patterns performed in soccer (Vescovi and McGuigan, 2008). To optimize the assessment procedure among young soccer players, the reliability and usefulness of the ICODT across different age categories need to be established. Moreover, the relationship between anthropometric variables and COD performance in young soccer players of different age categories has not been fully investigated.

Based on the considerations described above, the aims of the present study were (1) to compare ICODT performance across different age categories of young elite soccer players (U-8, U-10, U-12, and U-14); (2) to evaluate the reliability and usefulness of the ICODT when differentiating between age categories; and (3) to evaluate the possible role of body size variables (i.e., possible scaling effects) on the test outcomes. The expected results could be of critical importance for the future use of the ICODT in routine testing of young soccer players.

\section{Methods}

\section{Participants}

In total, 194 male, national-level soccer players who played in several different positions were enrolled in the study (U-8: $n=56$, age $=8.47$ \pm 0.26 years; $\mathrm{U}-10: \mathrm{n}=39$, age $=9.88 \pm 0.52$ years; $\mathrm{U}-12: \mathrm{n}=73$, age $=12.44 \pm 0.36$ years; and $\mathrm{U}-14: \mathrm{n}=$ 26 , age $=13.58 \pm 0.70$ years). The maturation status of the participants was determined by the predicted age at peak height velocity (APHV) (Malina et al., 2014) (Table 1). According to the classification of the Union of European Football Associations (UEFA), the players belonged to four 
different categories. Due to UEFA-imposed age limits, the actual average age difference between the U-10 and U-12 groups is more than 2.5 years, while the average age difference between the U-12 and U-14 groups is slightly more than one year. The anthropometric data of subjects in each group are also shown in Table 1.

Regarding their training experience, on average, the U-8 and U-10 groups had been playing soccer for at least 4 years, while the U-12 and U-14 groups had been playing soccer for more than 6 years. In terms of activity, the U-8 and U-10 groups participated in three $1.5 \mathrm{~h}$ training sessions per week and played a $50 \mathrm{~min}$ match each weekend. The U-12 and U-14 groups participated in four weekly training sessions of the same duration and played a $70 \mathrm{~min}$ match each weekend.

In accordance with the 1975 Declaration of Helsinki, the human subject committee of the local institution (i.e., the Higher Institute of Sport and Physical Education of Ksar Said, Tunis, Tunisia) approved this study. Informed consent was received from both the participants and their parents. The participants were provided with detailed information regarding the purpose and the potential risks of the study.

\section{Procedures}

The first part of this study aimed to establish the reliability and usefulness of the ICODT across different age groups. The evaluation was conducted during the second half of the competitive season (March-April 2013). The players were tested using the ICODT twice (the test and retest) with an interval of at least $72 \mathrm{~h}$ between tests (Stewart et al., 2014). Each subject participated in four sessions designed to familiarize the subjects with the ICODT two weeks prior to the first test. All tests were performed outdoor on an artificial turf pitch at the same time of day (between 5 and $7 \mathrm{pm}$ ) in calm conditions at temperature and humidity of 23$26^{\circ} \mathrm{C}$ and $51-59 \%$, respectively. Participants wore their regular training uniform and soccer cleats. They were instructed to maintain consistent dietary and sleeping patterns for 48 hours prior to each session and to refrain from strenuous activity for $24 \mathrm{~h}$ prior to each session.

All athletes performed three trials during both the test and retest, and the best performance was used for further analysis. A 3 min recovery period was provided between trials. The second part of the study involved a comparison of the ICODT performances among different age categories by recording the best performance during the retest session for all groups.

\section{Anthropometry}

The same researcher performed all anthropometric measurements. The anthropometric variables considered were body height (accuracy of $0.1 \mathrm{~cm}$; Hotain, UK) and body mass (accuracy of $0.1 \mathrm{~kg}$; Tanita BF683W, Munich, Germany). During the measurement procedures, the participants were barefoot and wore only shorts.

Illinois COD test

The dimensions and route directions for the ICODT were in accordance with established methods (Amiri et al., 2010, Figure 1). The ICODT involves placing four markers to indicate a $10 \mathrm{~m}$ by $5 \mathrm{~m}$ area. In the center of the area, four markers are placed $3.3 \mathrm{~m}$ apart. The participant starts in the prone position with his chin touching the surface of the starting line. He accelerates for 10 $\mathrm{m}$, turns around, returns to the starting line, swerves in and out of four markers, and finally completes a second $10 \mathrm{~m}$ sprint to finish the ICODT speed course. Participants in this study were instructed to run around the markers rather than cross them. If a participant failed to follow these instructions, the trial was terminated and restarted after a $3 \mathrm{~min}$ recovery period (Amiri et al., 2010). The performance outcomes were collected using an electronic timing system (Microgate SRL, Bolzano, Italy).

\section{Statistical analysis}

Data are presented as the mean and standard deviation (SD). Data were tested for normal distribution using the Shapiro-Wilk test. Systematic bias was investigated using a dependent $\mathrm{t}$-test to evaluate the hypothesis that there was a significant difference between the test and retest sample means. The relative reliability of the ICODT was determined by calculating the intraclass correlation coefficient (ICC). A value of 0.7-0.8 was considered as questionable, and a value $>0.9$ was considered as high (Vincent, 1999). Absolute reliability was analyzed using the standard error of measurement (SEM) expressed as a coefficient of variation (CV). A SEM of $5 \%$ was set as the criterion for good absolute reliability. The SEM was calculated by dividing 
the SD of the difference between scores by $\sqrt{2}$ (Hachana et al., 2013; Hopkins, 2000).

The smallest worthwhile change (SWC) was determined to establish the usefulness of the ICODT (Atkinson and Nevill, 1998). The usefulness of the test was assessed by comparing the SWC and the SEM. The SWC was determined by multiplying the between-subject SD by 0.2 (SWC 0.2$)$ (Gonzalo-Skok et al., 2014, 2015; Hopkins, 2001), which corresponded to a small effect; 0.6 (SWC0.6) corresponding to a moderate effect; and 1.2 (SWC 1.2$)$, which corresponded to a large effect. If the SEM was smaller than the SWC, the ability of the test to detect a change was rated as "good", and if the SEM was equal to the SWC, then the test was rated as "ok". However, if the SEM was greater than the SWC, then the test was rated as "marginal" (Liow and Hopkins, 2003). One-way analysis of variance (ANOVA) was used to evaluate between-group differences. In case of a significant difference, the Bonferroni or T2 of the Tamhane post hoc test (when the homogeneity of variance assessed by the Levene's test was violated) was used. To evaluate the practical significance of the observed differences, the effect size (ES) was also determined and rated according to the scale proposed by Cohen (1998), where 0.2, 0.5 and 0.8 were considered small, medium and large, respectively. Pearson's correlations were used to determine the relationship between ICODT performance and anthropometric variables. Cohen (1998) suggested that an absolute correlation coefficient of 0.2-0.4 was small, 0.5-0.7 was moderate, and $>0.7$ large. The criterion for significance for all tests was set at $p<0.05$. All statistical analyses were conducted using SPSS v.19.0 for Windows (SPSS, Inc, Chicago, IL, USA).

\section{Results}

The results of ANOVA revealed significant between-group differences for body mass, height and APHV, although not for the body mass index (BMI). Only the post hoc comparisons between the U-12 and U-14 groups failed to reveal significant differences in any of the tested variables (Table 1).

The test-retest results of the ICODT are shown in Table 2. Taken together, the data suggest exceptionally high reliability of the ICODT in each age group. All ICC values were well above 0.90, and the SEM values, expressed as $\mathrm{CVs}$, were under $5 \%$. Based on the usefulness analysis, the ICODT could detect small changes in performance in the U-10 and U-12 groups. However, in the U-8 and U-14 groups, the same test could detect only moderate changes in performance.

Regarding the differences in ICODT test scores among groups, between-group ANOVA revealed a significant main effect of group $(\mathrm{F}=$ $27.47_{(3,193) ;} p<0.001$; Figure 1). The U-10 group performed better than the U-8 group $(p<0.001$; ES $=0.78$ ). Similarly, the U-14 and U-12 groups performed better than the $\mathrm{U}-10$ and $\mathrm{U}-8$ groups ( $p$ $<0.02$, ES: 0.72 to 1.58 ). However, there was no statistically significant difference between the U12 and $\mathrm{U}-14$ groups $(p>0.05, \mathrm{ES}=0.29)$.

Finally, to assess whether body size affected performance in the ICODT, the relationships between the ICODT and both body mass and height were assessed in each age group. A total of 8 correlations were tested; however, none of the 8 resulting correlation coefficients (4 groups $\mathrm{x} 2$ body size indices) were close to significant. The correlation coefficients ranged from -0.30 to 0.15 (all $p>0.2$ ).

\section{Discussion}

The primary aims of the current study were to assess whether the ICODT provided a reliable outcome measure when used with young elite soccer players, to make comparisons across age categories, and to evaluate the effect of body size (i.e., possible scaling effects) on test performance. The main findings of the present study were that the ICODT was a highly reliable and sufficiently useful test for young elite soccer players. In addition, our results showed no significant relationship between body mass or height and ICODT performance in any age group, suggesting that this test did not require normalization for body size.

The reliability of the ICODT per se has been well established as an essential property of the testing outcomes (Cohen, 1998). The results of the present study indicate that the ICODT is a highly reliable COD test in young soccer players. Our results are in accordance with those shown in both adult athletes (Hachana et al., 2013) and young soccer players. In particular, high ICC values in conjunction with low SEM values might support the use of the ICODT in young soccer players and possibly in athletes participating in other sports in which COD is important for success. 


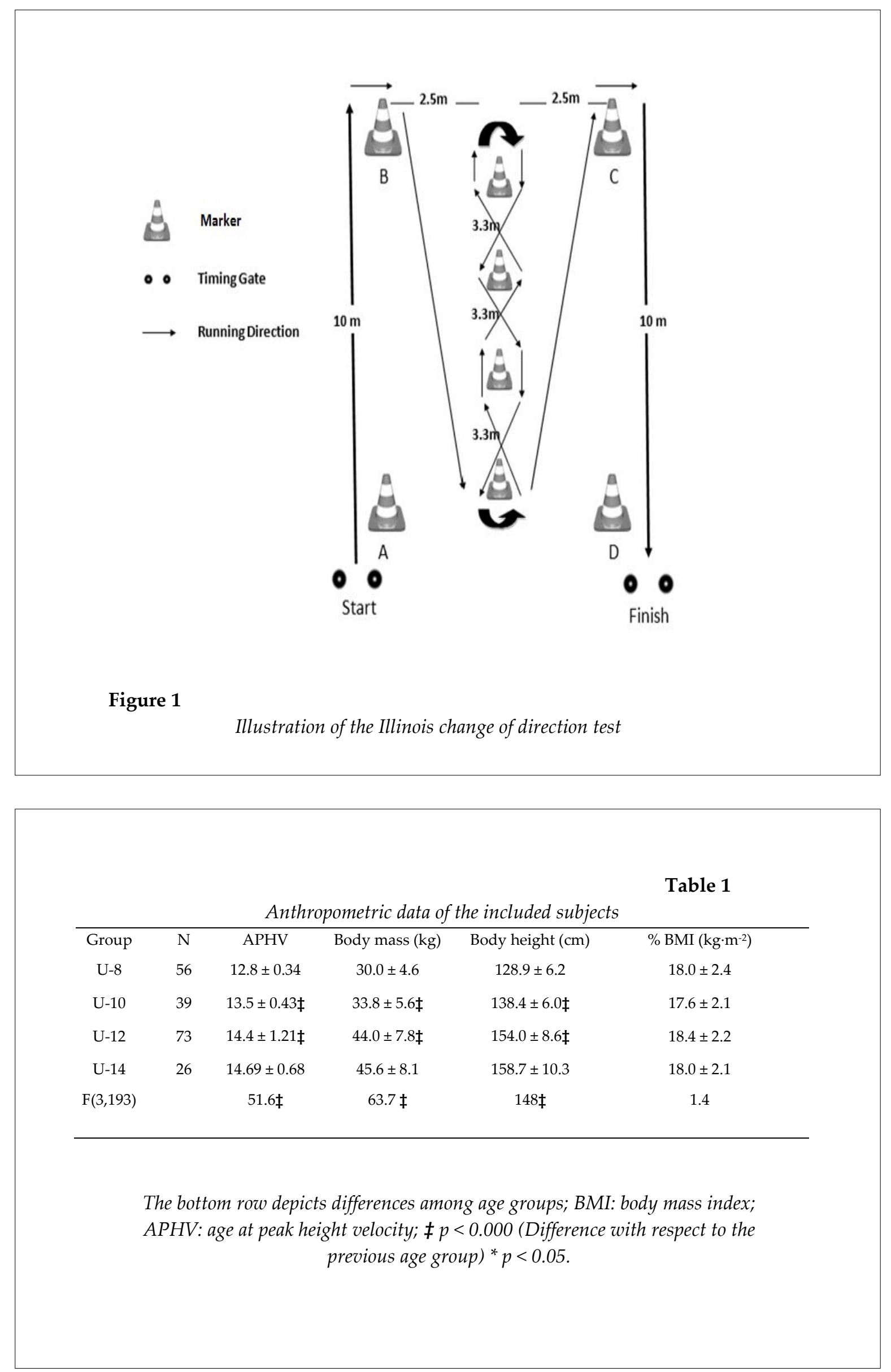

(C) Editorial Committee of Journal of Human Kinetics 


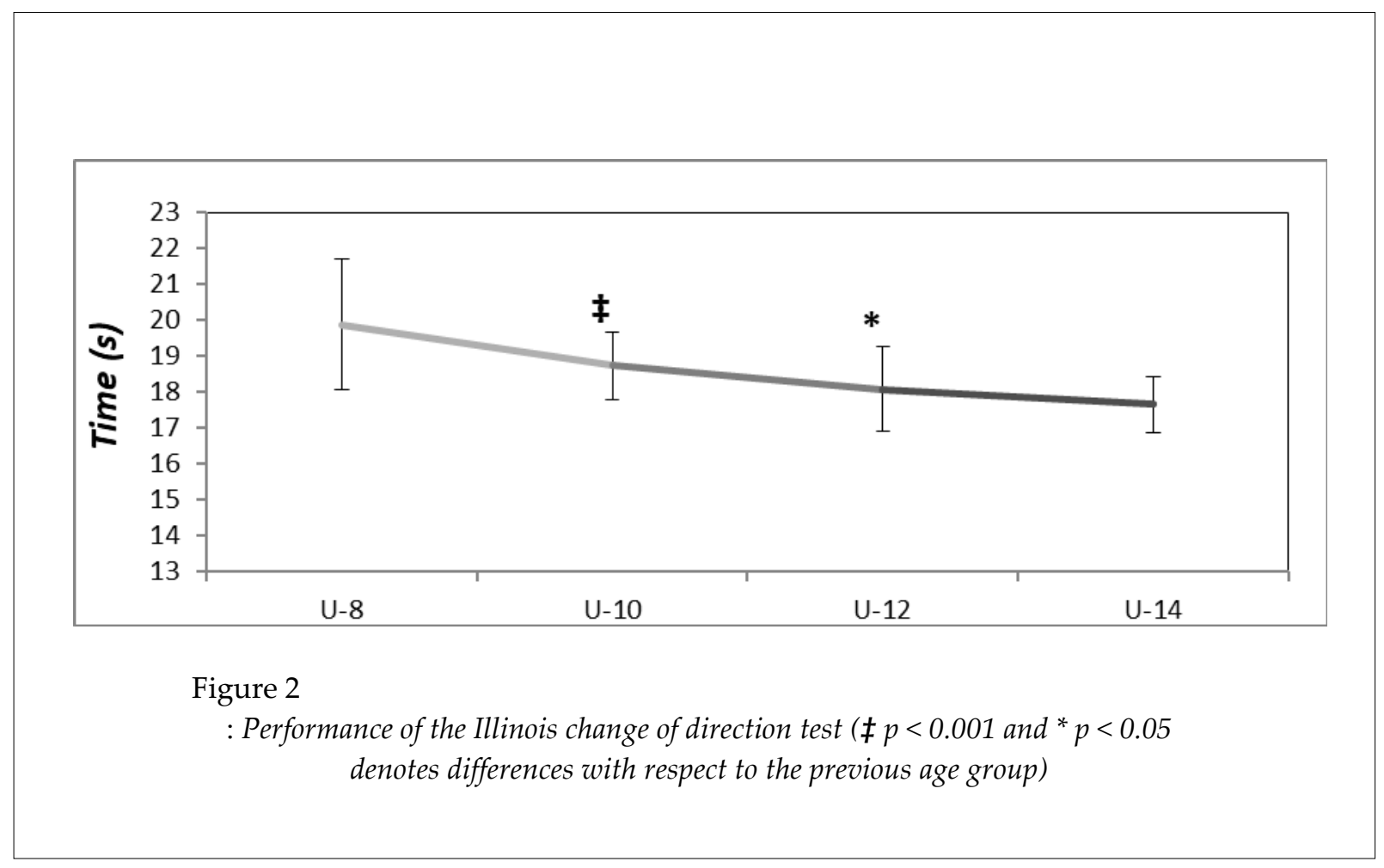

igure 2

denotes differences with respect to the previous age group)

Table 2

Performance and reliability of the Illinois change of direction test performance

\begin{tabular}{|c|c|c|c|c|c|c|c|c|c|}
\hline $\begin{array}{l}\text { Gro } \\
\text { up }\end{array}$ & $\begin{array}{c}\text { Trial } 1 \\
\text { (s) }\end{array}$ & $\begin{array}{l}\text { Trial } \\
2(s)\end{array}$ & $\mathrm{p}$ & ICC & SWC0.2 (s) & $\begin{array}{l}\text { SWC0 } \\
.6(\mathrm{~s})\end{array}$ & $\begin{array}{c}\text { SWC1. } \\
2(\mathrm{~s})\end{array}$ & $\begin{array}{l}\text { SE } \\
\text { M( } \\
\text { s) }\end{array}$ & $\begin{array}{l}\text { SEM as } \\
\text { CV (\%) }\end{array}$ \\
\hline U-8 & 20.27 & 20.21 & $\begin{array}{c}0.4 \\
1\end{array}$ & $0.95(0.91-0.97)$ & $\begin{array}{c}0.23 \\
\text { (marginal) }\end{array}$ & $\begin{array}{l}0.7 \text { (go } \\
\text { od) }\end{array}$ & $\begin{array}{c}1.4 \\
\text { (good) }\end{array}$ & $\begin{array}{c}0.2 \\
7\end{array}$ & 1.35 \\
\hline $\mathrm{U}-10$ & 18.87 & 18.91 & $\begin{array}{c}0.5 \\
3\end{array}$ & $0.96(0.92-0.98)$ & $\begin{array}{c}0.19 \\
\text { (good) }\end{array}$ & $\begin{array}{c}0.58(\mathrm{~g} \\
\text { ood })\end{array}$ & $\begin{array}{c}1.16 \\
\text { (good) }\end{array}$ & $\begin{array}{c}0.1 \\
4\end{array}$ & 0.72 \\
\hline $\mathrm{U}-12$ & 18.121 & $\begin{array}{c}18.12 \\
4\end{array}$ & $\begin{array}{c}0.9 \\
6\end{array}$ & $0.96(0.94-0.98)$ & 0.25 (good) & $\begin{array}{c}0.74(\mathrm{~g} \\
\text { ood })\end{array}$ & $\begin{array}{c}1.5 \\
\text { (good) }\end{array}$ & $\begin{array}{c}0.2 \\
3\end{array}$ & 1.26 \\
\hline U-14 & 17.88 & 17.78 & 0.3 & $0.92(0.81-0.96)$ & $\begin{array}{c}0.17 \\
\text { (marginal) }\end{array}$ & $\begin{array}{c}0.51(\mathrm{~g} \\
\text { ood })\end{array}$ & $\begin{array}{c}1.02 \\
(\text { good) }\end{array}$ & $\begin{array}{c}0.2 \\
2\end{array}$ & 1.26 \\
\hline
\end{tabular}

s: second; ICC: intraclass correlation coefficient (corresponding 95\% confidence interval underneath); SWC: smallest worthwhile change $(0.2 \times S D=S W C 0.2 ; 0.6$ $\times S D=S W C 0.6 ; 1.2 \times S D=S W C 1.2) ; S E M$ : standard error of measurement; $p$ : level of significance (one-group $t$-test of the difference between the trials) 
These results are within the same range of reliability as those observed in male team sport athletes (ICC $=0.96$ and SEM $=0.19 \mathrm{~s}$; Hachana et al., 2013). In a recent study conducted on U-14 soccer players, Hachana et al. (2014) reported an ICC value of 0.94 and SEM of 0.23 s $(1.24 \%)$, which are also in line with the present findings. In addition, our results are in agreement with those reported by Hulse et al. (2013) who found ICC values of 0.89 and 0.84 and a CV of $2.5 \%$ among U-9 to U-11 and U-12 to U-14 soccer players, respectively, in a COD test course. The high reliability of the ICODT observed with both adult (Hachana et al., 2013) and young athletes might support its use by coaches and fitness trainers who need to test COD ability in soccer players, whose performance is significantly based on this ability.

The ICODT's usefulness was assessed by comparing the SEM values to their respective SWC values (Hachana et al., 2014; Lockie et al., 2013). The results showed that the ICODT's ability to detect small changes in performance can be rated as "good" in both U-10 and U-12 soccer players as their SWC0.2 values were higher than their respective SEMs. However, the ICODT could only detect moderate changes in performance in U-8 and U-14 soccer players because their SWC0.6 values were higher than their respective SEMs. Other study revealed an "ok" ability of the ICODT to detect small changes in performance (Hachana el al., 2014). Therefore, although the SEM (Hachana et al., 2013, 2014; Lockie et al., 2013) is relatively low in all groups, the usefulness of the ICODT remains a subject of debate.

In the present study, the differences in terms of anthropometric measures were statistically significant except for the findings between the U-12 and U-14 groups. This phenomenon could be explained by the small difference in chronological and biological age between those 2 groups, which was only slightly greater than 1 year. The similar age could also explain why no difference in agility was observed between the 2 groups as both groups performed better than either the U-8 or U-10 group. Collectively, these observations might be explained by growth and maturation levels, which also affected the performance of these individuals during high-intensity exercises (Abrantes et al., 2004; Zafeiridis et al., 2005).
However, taller and heavier individuals should be both stronger and more powerful than shorter and lighter ones (Crewther et al., 2011; Jacobson, 2015; Jaric, 2003; Nedeljkovic et al., 2009).

It has been shown that body size can confound the outcomes of various fitness tests, but likely not the velocity of the tested movement (Jaric, 2003). Since COD performance is based partly on movement velocity, which is typically developed over short time intervals, it is not surprising that we found no relationship between ICODT performance and the indices of body size in any of the four subject groups. However, other studies have suggested that agility could be considerably influenced not only by straight-line running velocity, but also by lower-limb strength and power as well as anthropometric variables (Lloyd and Oliver, 2012). In addition, the subjects within each age group should be at different maturation levels, and those who are more mature are likely to have a larger body size and greater physical ability (Malina et al., 2004). The effects of growth and maturation are known to result in spurious positive relationships between body size and movement performance in young athletes (Jaric et al., 2002; Nedeljkovic et al., 2007). Therefore, our results add to the evidence supporting the use of the ICODT as a standard agility test in various populations. The ICODT appears to be relatively insensitive to possible differences in maturation level among young athletes of the same age and, therefore, does not require additional body size normalization.

Some limitations of the present study must be addressed. First, the present results were obtained from a sample comprising only young male athletes. Therefore, coaches and sports scientists should be cautious when generalizing the findings to female players as growth, qualitative muscular factors and performance variables in females are not in parallel with those of males (Armstrong et al., 2001; Martin et al., 2004). An evaluation of the ICODT in other populations of athletes certainly deserves attention. Finally, although the present results are encouraging regarding the use of the ICODT for routine testing, direct comparisons between the ICODT and other COD tests are needed before recommendations for standard testing can be made.

Our findings indicate that the ICODT is a 
reliable and sufficiently useful test for assessing COD in young male soccer players. The test does not require normalization for body size even when it is used in young populations with varying levels of maturation. Finally, the ICODT could have a high level of ecological validity for soccer, which requires rapid movement initiation and transient sprinting with changes in direction. Therefore, our findings strongly support the use of the ICODT as a standard test of COD ability in young male soccer players, whose performance depends significantly on COD ability.

\section{References}

Abrantes C, Macas V, Sampaio J. Variation in football players' sprint test performance across different ages and levels of competition. J Sports Sci Med, 2004; 3: 44-49

Amiri KM, Sahebozamani M, Tabrizi KG, Yusof AB. Acute effect of different stretching methods on Illinois agility test in soccer players. J Strength Cond Res, 2010; 24: 2698-2704

Armstrong N, Welsman JR, Chia MY. Short term power output in relation to growth and maturation. $\mathrm{Br} \mathrm{J}$ Sports Med, 2001; 35: 118-124

Atkinson G, Nevill A. Statistical methods for assessing measurement error (reliability) in variables relevant to sports medicine. Sports Med, 1998; 26: 217-238

Bangsbo J. Time and motion characteristics of competition soccer. Science Football, 1992; 6: 34-40

Bloomfield J, Polman R, O'Donoghue P. Physical demands of different positions in FA Premier League soccer. J Sports Sci Med, 2007; 6: 63-70

Cohen J. Statistical Power Analysis for the Behavioural Sciences (2nd Ed.). Hillsdale, NJ: Erlbaum Associates; 1998

Chiodera P, Volta E, Gobbi G, Milioli MA, Mirandola P, Bonetti A, Delsignore R, Bernasconi S, Anedda A, Vitale M. Specifically designed physical exercise programs improve children's motor abilities. Scand J Med Sci Sports, 2008; 18: 179-187

Crewther BT, McGuigan MR, Gill, ND. The ratio and allometric scaling of speed, power, and strength in elite male rugby union players. J Strength Cond Res, 2001; 25(7): 1968- 1975

Davids K, Lees A, Burwitz L. Understanding and measuring coordination and control in kicking skills in soccer. Implications for talent identification and skill acquisition. J Sports Sci , 2000; 18: 703-714

Draper JA, Lancaster MG. The 505 test: A test for agility in the horizontal plane. Aust J Sci Med Sports, 1985; 17(1): 15-18

Gonzalo-Skok O, Tous-Fajardo J, Arjol-Serrano JL, Mendez-Villanueva A. Determinants, reliability, and usefulness of a bench press repeated power ability test in young basketball players. J Strength Cond Res, 2014; 28(1): 126-33

Gonzalo-Skok O, Tous-Fajardo J, Suarez-Arrones L, Arjol-Serrano JL, Casajús JA, Mendez-Villanueva A. Validity of the V-cut Test for Young Basketball Players. Int J Sports Med, 2015; 36(11): 893-9

Hachana Y, Chaabene H, Nabli MA, Attia A, Moualhi J, Farhat N, Elloumi M. Test retest reliability, criterion-related validity, and minimal detectable change of the Illinois agility test in male team sport athletes. J Strength Cond Res, 2013; 27: 2752-9

Hachana Y, Chaabene H, Ghada BR, Khlifa R, Aouadi R, Chamari K, Gabbett T. Validity and Reliability of New Agility Test among Elite and Sub-elite under 14-Soccer Players. Plos One, 2014; 9-4

Hopkins WG. Measures of Reliability in Sports Medicine and Science. Sports Med, 2000; 30: 1-15

Hopkins WG, Schabort EJ, Hawley JA. Reliability of power in physical performance tests. Sports Med, 2001; 
31: $211-234$

Jacobson BH. A comparison of allometric scaling methods for normalizing strength, power and speed in American football players. J Sports Med Phys Fitness, 2015; 55: 621-7

Jakovljevic ST, Karalejic MS, Pajic ZB, Macura MM, Erculj FF. Speed and agility of 12- and 14-year-old elite male basketball players. J Strength Cond Res, 2012; 26: 2453-2459

Jaric S. Role of body size in the relation between muscle strength and movement performance. Exerc Sport Sci Rev, 2003; 31: 8-12

Jaric S, Ugarkovic D, Kukolj M. Evaluation of methods for normalizing strength in elite and young athletes. J Sports Med Phys Fitness, 2002; 42: 141-151

Liow DK, Hopkins WG. Velocity specificity of weight training for kayak sprint performance. Med Sci Sports Exerc, 2003; 35: 1232-1237

Lloyd RS, Oliver JL. The youth physical development model: A new approach to long-term athletic development. Strength Cond J, 2012; 34: 61-72

Lloyd RS, Read P, Oliver JL, Meyers Robert WM, Nimphius S, Jeffreys I. Considerations for the Development of Agility during Childhood and Adolescence. Strength Cond J, 2013; 35 (3): 2-11

Little T, Williams AG. Specificity of acceleration, maximum speed, and agility in professional soccer players. J Strength Cond Res, 2005; 19: 76-78

Lockie RG, Schultz AB, Callaghan SJ, Jeffriess MD, Berry SP. Reliability and Validity of a New Test of Change-of-Direction Speed for Field- Based Sports: the Change-of-Direction and Acceleration Test (CODAT). J Sports Sci Med, 2013; 12: 88-96

Luhtanen P. Biomechanical aspects. In: Football (Soccer) Handbook of Sports Medicine and Science, ed. B. Ekblom. Blackwell Scientific Publications, London; 1994

Malina RM, Eisenmann JC, Cumming SP, Ribeiro B, Aroso J. Maturity-associated variation in the growth and functional capacities of youth football (soccer) players 13-15 years. Eur J Appl Physiol, 2004; 91(5-6): $555-62$

Malina RM, Bouchard C, Bar-Or O. Growth, Maturation and Physical Activity. Champaign, IL: Human Kinetics; 2004

Malina RM, Kozieł, SM. Validation of maturity offset in a longitudinal sample of Polish boys. J Sports Sci, 2014; 32(5): 424-37

Martin RJ, Dore E, Twisk J, VanPraagh E, Hautier CA, Bedu M. Longitudinal changes of maximal short-term peak power in girls and boys during growth. Med Sci Sports Exerc, 2004; 36: 498-503

Mirkov DM, Kukolj M, Ugarkovic D, Koprivica VJ, Jaric, S. Development of anthropometric and physical performance profiles of young elite male soccer players: a longitudinal study. J Strength Cond Res, 2010; 2677-82

Nedeljkovic A, Mirkov DM, Kukolj M, Ugarkovic D, Jaric, S. Effects of maturation on the relationship between physical performance and body size. J Strength Cond Res, 2007; 21: 245-50

Nedeljkovic A, Mirkov DM, Bozic P, Jaric S. Tests of muscle power output: The role of body Size. Int J Sports Med, 2009; 30: 100-106

Reilly T, Bangsbo J, Franks A. Anthropometric and physiological predispositions for elite Soccer. J Sports Sci, 2000; 18(9): 669-83

Sheppard JM, Young WB. Agility literature review: Classifications, training and testing. J Sports Sci, 2006; 24: 919-932 
Stewart PF, Turner, AN, Miller SC. Reliability, factorial validity, and interrelationships of five commonly used change of direction speed tests. Scand J Med Sci Sports, 2014; 24(3): 500-6

Vänttinen T, Blomqvist M, Nyman K, Häkkinen K. Changes in body composition, Hormonal Status, and physical fitness in 11-, 13-, and 15-year-old Finnish regional youth soccer Players during a two-year follow up. J Strength Cond Res, 2011; 25: 3342- 3351

Vescovi JD, McGuigan MR. Relationships between sprinting, agility, and jump ability in female athletes. J Sports Sci, 2008; 26: 97-107

Zafeiridis A, Dalamitros A, Dipla K, Manou V, Galanis N, Kellis S. Recovery during high-Intensity intermittent anaerobic exercise in boys, teens and men. Med Sci Sports Exerc, 2005; 37: 505-512

\section{Corresponding author:}

\section{Dr. Chaabene Helmi}

Tunisian Research Laboratory "Sports Performance Optimization",

National Center of Medicine and Science in Sports (CNMSS), Tunis, Tunisia

High Institute of Sports and Physical Education, Kef, University of Jendouba, Tunisia

APP E28, Résidence El Walid 2, Aghba Tunis, 2087.Phone number: 0021652217114

Email: chaabanehelmi@hotmail.fr 